\title{
Analysis of the geomechanical characterization of coarse granular materials using the parallel gradation method
}

\author{
Análisis de la caracterización geomecánica de materiales granulares gruesos usando \\ el método de granulometría paralela \\ Fecha de entrega: 16 de diciembre 2019 \\ Fecha de aceptación: 24 de abril 2020
}

\section{Leonardo Dorador ${ }^{1}$ and Felipe A. Villalobos ${ }^{2}$}

\author{
${ }^{1}$ Arcadis Chile, Antonio Varas 621, Providencia, Región Metropolitana de Santiago, Chile, leonardo.dorador@arcadis.com \\ ${ }^{2}$ Laboratory of Geomaterials, Department of Civil Engineering, Faculty of Engineering, Universidad Católica de la Santísima \\ Concepción, Concepción, Chile, avillalobos@ucsc.cl (Orcid: 0000-0002-5419-3958)
}

The geotechnical characterization of coarse granular materials such as very coarse-grained soils, rockfills, mining waste rocks and related materials is one of the key themes in geotechnical engineering but least studied and developed. Although there are some geotechnical standards and accepted geotechnical practice, there is not a standard for size-scaling, which is a critical step in advanced stage engineering (i.e. detailed design) on large structures involving this kind of materials. Several size-scaling techniques are available for use, with advantages and disadvantages. Among these, the parallel gradation method PGM (also known as homothetic grain size distribution), is one of the current practices and used for more than 50 years, but surprisingly just a few studies have corroborated its capability, and under specific material types. This work assesses a detailed database covering the development of this method from its first uses up to now. The application of this method is analysed based mainly on the material maximum internal friction angle and the Marsal's particle breakage index $\left(B_{g}\right)$.

Keywords: coarse granular materials, parallel gradation method, geotechnical characterization, size-scaling, shear strength, particle breakage
La caracterización geotécnica de materiales granulares gruesos tales como suelos de granulometría muy gruesa, enrocados, lastres de mina y otros materiales semejantes, es uno de los temas clave, pero menos abordados y estudiados en ingeniería geotécnica. Aunque existen algunas normas y cierta práctica geotécnica aceptada, no hay normativa de escalamiento de tamaño, lo cual representa un punto crítico en el avance de la ingeniería (diseño de detalle) en estructuras grandes que involucran este tipo de materiales. Varias técnicas de escalamiento de tamaño están disponibles, las cuales tienen ventajas y desventajas. Entre estas técnicas, el método de granulometría paralela (también conocido como granulometrías homotéticas), es uno de los usados actualmente en la práctica por más de 50 años, pero sorpresivamente solo unos pocos estudios han corroborado su capacidad y usando materiales especificos. Este trabajo examina una base de datos detallada abarcando el desarrollo de este método desde sus primeros usos hasta ahora. La aplicación de este método se analiza basándose principalmente en el ángulo de fricción interna máximo y el parámetro de rotura de partículas de Marsal $\left(B_{g}\right)$.

Palabras clave: materiales granulares gruesos, método de granulometría paralela, caracterización geotécnica, escalamiento de tamaño, resistencia al corte, rotura de partículas

\section{Introduction}

The size-scaling in the geotechnical characterization of coarse granular materials is a key topic, not only in early level engineering projects (i.e. conceptual and pre-feasibility), but also under advanced level projects (i.e. feasibility and detailed engineering). Although the scalping method seems to be the most common size- scaling technique in laboratory testing centers (Dorador, 2018), the parallel gradation method (PGM) is the most recurrent method for scaling the geomechanical properties on coarse granular materials (CGM) in research studies, specially regarding geotechnical characterization of rockfills, crushed ballasts, waste rocks, and alluvial/fluvial materials. The PGM consists in scaling coarse particles to 
smaller particles using the same scale ratio for all particle sizes.

This paper presents a comprehensive analysis of the application of PGM in coarse granular materials CGM. The use of the PGM will depend on the type of CGM; so, a geotechnical description of the types of coarse granular materials is introduced and developed through this paper. Particularly, it is highlighted that the CGM need to be classified in two main groups (sedimentary coarse soils and rock-piles). Also, previous experimental studies are analysed in terms of the effectiveness of the PGM on different types of CGM. As the PGM has some limitations on its use, recommendations for using the PGM are presented at the end of the work.

\section{Classification of CGM in terms of its origin}

Coarse granular materials CGM, defined as granular materials containing particles larger than $75 \mathrm{~mm}$, can be quite complex in terms of their mechanical properties' assessments. As its particle size distribution (PSD) can span several orders of magnitude in particle diameter, the intrinsic particle characteristic can change dramatically in size, which create difficulties when scaling from large to smaller samples. Therefore, each coarse-grained material should be analyzed independently in terms of its geological nature. As follow, several types of coarse-grained materials are presented and classified in two main groups in terms of their geomechanical characterization as shown in Figure 1 and further developed through this paper.

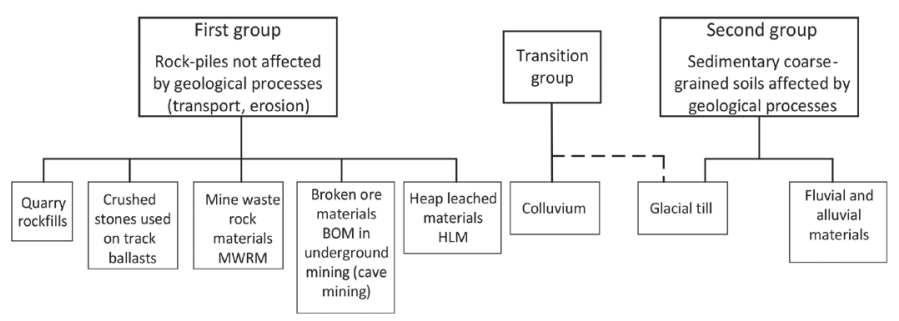

Figure 1: Classification of coarse granular materials

Rock-piles are commonly angular particles which are affected by a decrease in particle strength for larger sizes, while sedimentary CGM are comprised of fluvial and alluvial particles, mostly rounded and subrounded. On one hand, particle shape changes the density characteristics of CGM, and on the other hand, particle strength affects directly the shear strength of CGM. As a matter of fact, an interesting result is provided by Varadarajan et al. (2006), who shows maximum internal friction angles $\phi_{\text {max }}^{\prime}$ for different parallel gradations, finding that $\phi_{\text {max }}^{\prime}$ decreases or increases depending on whether the material is a riverbed or a quarry rockfill as shown in Figure 2. Tables 1 and 2 present authors and materials for which $\phi_{\text {max }}^{\prime}$ has resulted in an increase or a decrease for model gradations of smaller particle sizes.

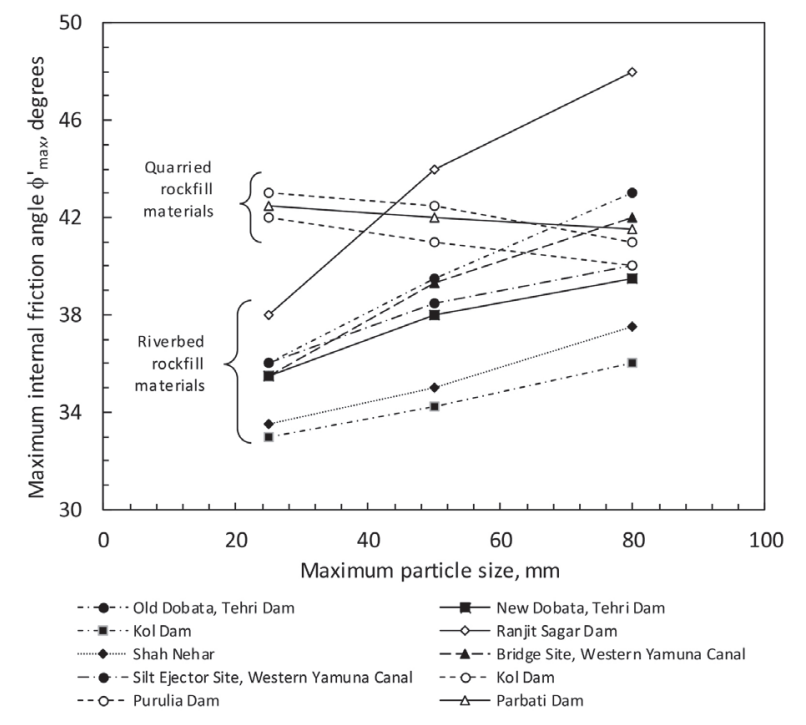

Figure 2: Variation of $\phi_{\max }^{\prime}$ with maximum particle size (Varadarajan et al., 2006)

Table 1: $\phi_{\text {max }}^{\prime}$ increases for model gradations of smaller particle sizes

\begin{tabular}{|l|l|}
\hline Author & Material* \\
\hline \multirow{3}{*}{ Marachi et al. (1969) } & Pyramid dam \\
\cline { 2 - 2 } & Oroville dam \\
\cline { 2 - 2 } & Crushed basalt \\
\hline Varadarajan et al. (2003) & Purulia dam \\
\hline Honkanadavar and Sharma (2016) & Kol dam (quarried) \\
\hline
\end{tabular}

Table 2: $\phi^{\prime}{ }_{\max }$ decreases for model gradations of smaller particle sizes

\begin{tabular}{|l|l|}
\hline Author & Material* \\
\hline Varadarajan et al. (2003) & Ranjit Sagar \\
\hline de la Hoz (2007) & P-1 (fluvial deposits) \\
\hline Dewangan et al. (2015) & Overburden dump sample \\
\hline Dorador (2010) & R.L. (Heap leach material) \\
\hline Kim and Ha (2014) ** & $\begin{array}{l}\text { Seomjin river (no } \\
\text { reinforcement) }\end{array}$ \\
\hline Honkanadavar and Sharma (2016) & Noa Dehing dam \\
\hline
\end{tabular}

*Materials tested under triaxial compression (CID).

** Direct shear tests 
Table 3 presents a summary of critical factors governing the mechanical properties on coarse-grained materials. All the materials listed above are defined with a fines content lower than $10 \%$ due to the influence of the fines on the mechanical properties of the overall material (Verdugo and de la Hoz 2006; de la Hoz 2007). Therefore, the PGM is not recommended for CGM which contain significant amount of fines (higher than 10\%). Materials with significant amount of fines can be found in glacial till, colluvium, fluvial and alluvial materials.

Table 3: Key factors to consider on mechanical properties on coarse-grained materials

\begin{tabular}{|l|c|c|c|}
\hline $\begin{array}{l}\text { Type of coarse- } \\
\text { grained material }\end{array}$ & $\begin{array}{c}\text { Particle's } \\
\text { segregation }\end{array}$ & $\begin{array}{c}\text { Mixtures } \\
\text { of weak } \\
\text { and strong } \\
\text { particles }\end{array}$ & $\begin{array}{c}\text { Strength } \\
\text { reduction for } \\
\text { larger particles }\end{array}$ \\
\hline Rockfill materials & Low-moderate & Low-moderate & High \\
\hline Mining waste rocks & High & High & High \\
\hline $\begin{array}{l}\text { Heap leached } \\
\text { materials }\end{array}$ & Low-moderate & High & Low-high \\
\hline $\begin{array}{l}\text { Broken ore } \\
\text { materials BOM }\end{array}$ & Very high & Very high & Very high \\
\hline Fluvial materials & N.A & Low-moderate & Low \\
\hline Alluvial materials & N.A & Low & Low \\
\hline $\begin{array}{l}\text { Colluvium } \\
\text { materials }\end{array}$ & N.A & Moderate & Moderate \\
\hline
\end{tabular}

\section{The parallel gradation method PGM}

The parallel gradation method PGM (also known as parallel gradation technique, parallel or homothetic grainsize distribution method) was presented by Lowe (1964), although Idel (1960) had also studied the method and Leslie (1963) conducted an empirical study using this method. The objective of the PGM is to scale coarse particles to smaller particles using the same scale ratio for all particle sizes. To this end, the particle size distribution (PSD) is scaled to a smaller size distribution curve under a semilogarithmic scale according to a similitude ratio $s$ as shown in Figure 3. In addition, the PGM assumes to maintain the same intrinsic particle characteristics of both original and scaled particles such as compressive strength, shape, and specific gravity. Although the objective of the PGM is to reproduce the geotechnical properties of CGM based on small samples, the practice indicates that the reproducibility is not accurate. This means that a criterion for effectiveness of the PGM on the geomechanical evaluation needs to be defined before discussing empirical results regarding PGM.

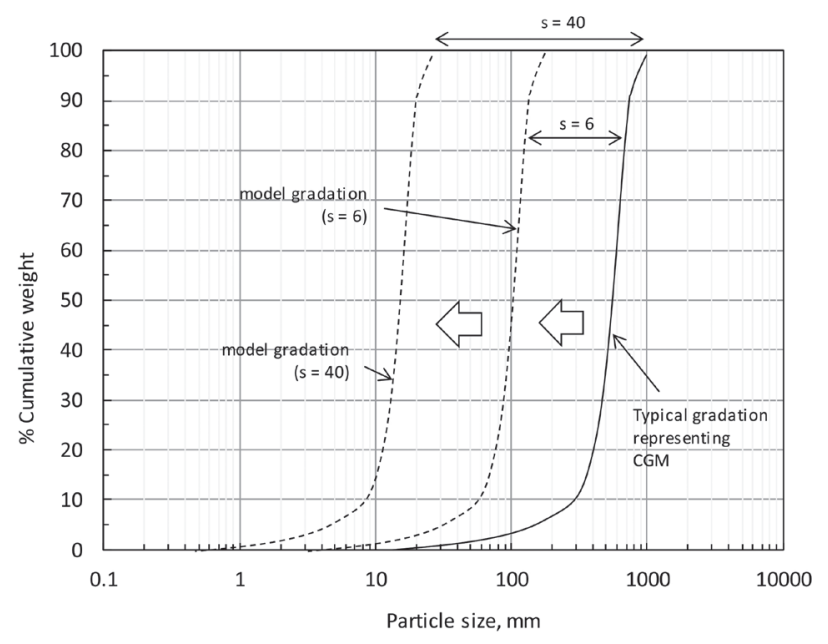

Figure 3: Parallel gradation method PGM on coarse-grained materials showing the ratio of similitudes

\section{Criteria for effectiveness of the PGM on geomechanical evaluation of CGM}

The objective of the PGM is to reproduce the original properties of CGM by means of model samples (scaled samples). This means that the results (e.g. shear strength) from model samples should be comparable to the original material. Then, it is practical to consider the error of repeatability as a mean to evaluate the effectiveness of the PGM in CGM. The repeatability of mechanical properties in CGM could be more difficult to reach in regard to other granular materials (e.g. sands). This is explained by the nature of well graded materials of CGM (e.g. uniformity coefficient $C_{\mathrm{u}}=50$ ), implying that under a random packing, the deformation characteristics and shear bands within the specimen could be developed in a distinct manner depending on the particle arrangement. Regarding this issue, not many studies have been published, although two valuable studies in sands and gravels under direct shear testing are discussed below as a means to define a criterion of the effectiveness of the PGM on CGM.

Bareither et al. (2006) found in backfill sands under direct shear testing that the difference in the maximum internal friction angle $\phi_{\text {max }}^{\prime}$ can be as low as $1.5^{\circ}$, for the same laboratory equipment and testing conditions. $\mathrm{Fu}$ and Dai (2015) also presented repeatability in direct shear tests. The testing programme consisted in five tests under the same material and test conditions for three different normal stresses $(143,286$ and $573 \mathrm{kPa})$. The results reported indicated differences of $\phi_{\text {max }}^{\prime}$ of 4,4 and $2.5^{\circ}$ for 
each normal stress respectively and then, an average of $3^{\circ}$ of variability in terms of $\phi_{\text {max }}^{\prime}$. Based on the previous, but limited, studies a difference of $3^{\circ}$ in $\phi^{\prime}{ }_{\max }$ may be assumed as a preliminary criterion for the effectiveness of the parallel gradation method PGM, while new empirical and numerical studies allow to define a detailed criterion to evaluate the effectiveness of the PGM.

\section{Background of PGM}

Although the use of the PGM is a common practice for geotechnical characterization of coarse-grained materials and it has been employed for more than 50 years, the mechanical property evaluation of CGM using the PGM has been comprehensively studied and corroborated empirically by Marachi et al. (1969), Becker et al. (1972), Jernigan (1998), Gesche (2002), de la Hoz (2007) and Hu et al. (2011). These authors have confirmed the effectiveness of the PGM for a ratio of similitude $s$ between 3 and 25 and for certain materials, which may differ with the practice of using this method. As an example, for a rockfill with maximum particle size of $1000 \mathrm{~mm}, s$ could be as large as 6 considering the use of a large triaxial testing equipment with a specimen diameter of $1 \mathrm{~m}$ and as large as $s=40$ for conventional triaxial testing for triaxial specimens of 150 $\mathrm{mm}$ diameter as shown in Figure 3.

The particle breakage phenomenon on shear tests can be considered as an alternative to verify the effectiveness of the parallel gradation method. Due to the particle's nature, rock-piles materials (first group material, according to Figure 1) can be subjected to a wide range of particle breakage, in contrast to sedimentary CGM (second group materials), comprised of fluvial and alluvial particles of high particle strength. In fact, sedimentary CGM are affected by low or negligible amount of particle breakage during shear testing, which can be corroborated on triaxial compression tests results under confining pressures between 50 and $600 \mathrm{kPa}$ (Gesche, 2002; de la Hoz, 2007; Dorador, 2010). Thus, particle breakage is discussed on CGM classified as rock-piles materials and the Marsal (1973)'s $B_{\mathrm{g}}$ index is considered. The parameter of grain breakage $B_{\mathrm{g}}$ is equivalent to the sum of the positive values of the differences $(\Delta \mathrm{W})$ between the percentage retained by weight under each particle size fraction before and after testing.

\section{Relevant experimental studies regarding PGM on CGM}

These experiments consider an original PSD with maximum particle sizes of gravel sizes and up. In addition, they consider a similarity ratio $s$ between the original and model gradation larger than 3. Also, the experiments presented as follow were triaxial compression tests on remoulded samples.

Leslie (1963) was probably the first author in publishing empirical data employing the PGM. Figure 4a shows Leslie's four parallel gradations on alluvial soil with subrounded to subangular particles and a largest similarity ratio $s$ of 8.3 among the four gradations. From triaxial tests with diameter and length specimens of $150 \mathrm{x} 351,152 \mathrm{x}$ 305 and $305 \times 701 \mathrm{~mm}$ and a confining pressure of $400 \mathrm{kPa}$, $\phi_{\text {max }}^{\prime}$ between 38 and $40^{\circ}$ were obtained as shown in Figure $4 \mathrm{~b}$. Although the void ratio diminishes slightly for larger particle sizes as shown in Figure 4b, the maximum difference of internal friction angle among each parallel gradation is 2 degrees. Thus, the Parallel Gradation Method was corroborated for this material, under a similitude ratio of 8 .
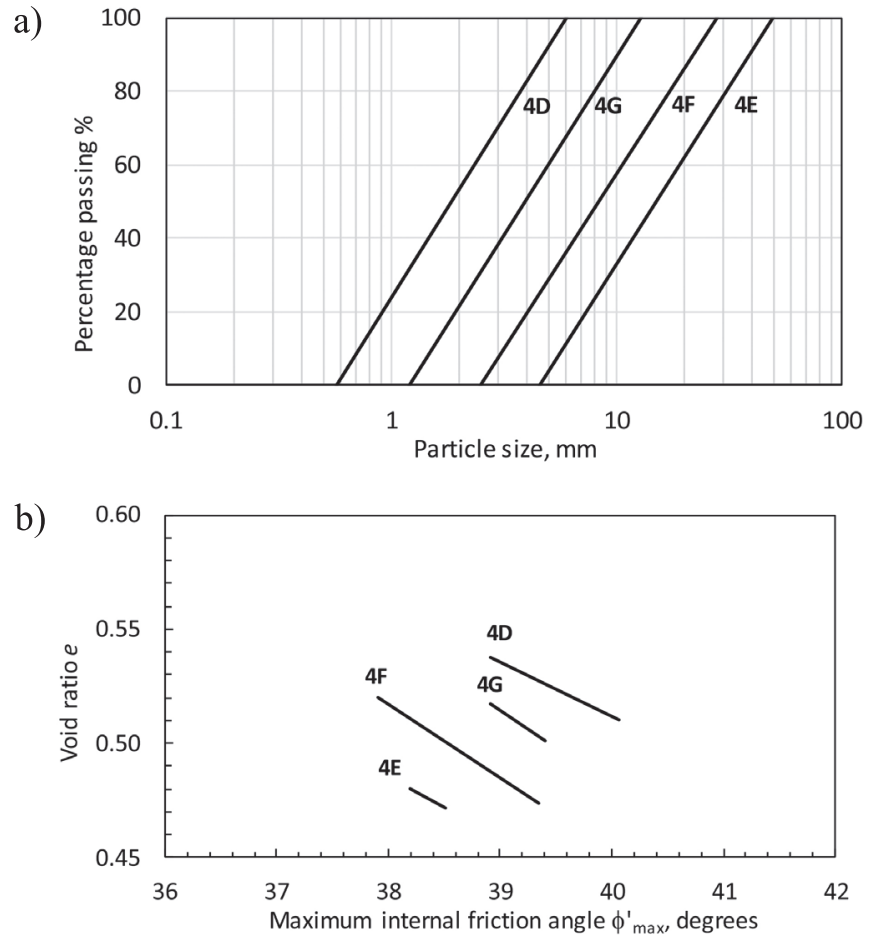

Figure 4: Triaxial compression test results reported by Leslie (1963). a) Parallel gradations and b) $\phi_{\max }^{\prime}$ versus void ratio 
Marachi et al. (1969) studied rockfill materials from different origins and properties. While the shear tests were triaxial compression for specimen diameter samples of 914 , 305 and $71 \mathrm{~mm}$, maximum particle diameter were of $D_{100}=$ 150,50 and $12 \mathrm{~mm}$. Consolidation pressures on specimens were $0.21,0.98,2.94$ and $4.55 \mathrm{MPa}$. The first material named as Pyramid dam consisted in an argillite rockfill from quarry blasting with very angular particles. The second material is a crushed basalt, consisting of a quarry rockfill with very angular particles. The third material is a rockfill material consisting of rounded particles from a meta-volcanic rock (amphibolite). Gradations are shown in Figure 5 and internal friction angle results are presented in Figure 6.

a)

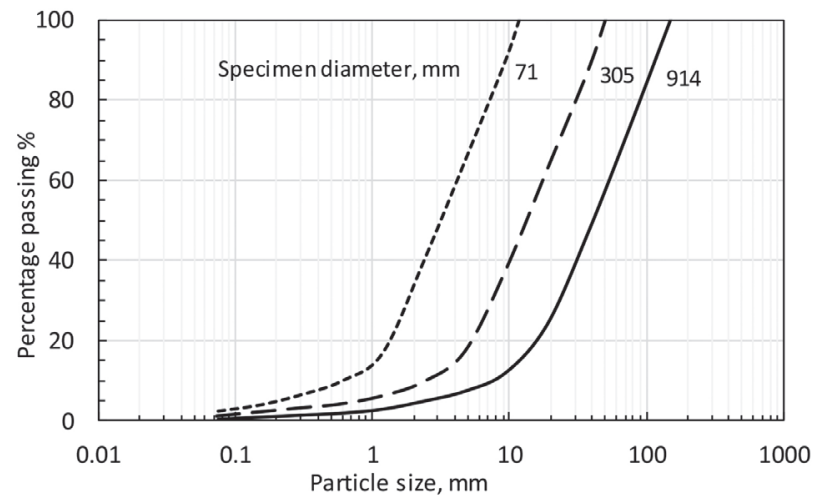

b)

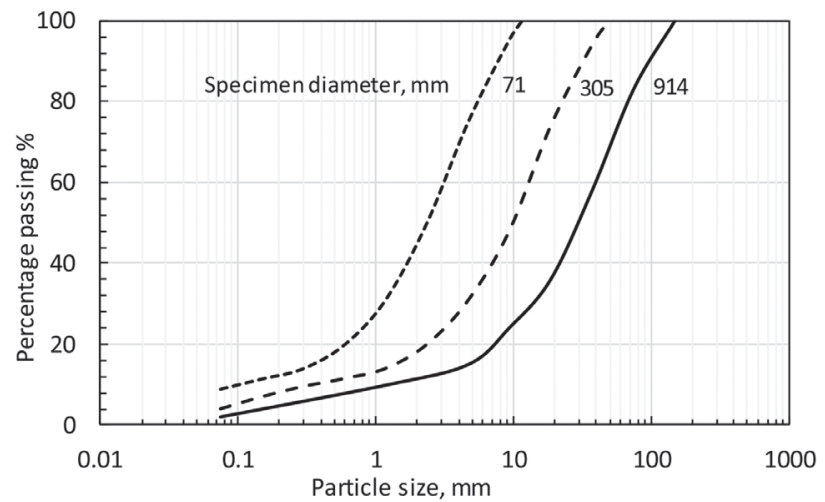

Figure 5: Gradations of: a) Pyramid dam material and crushed basalt material and b) Oroville dam material

Coincidently, for these three materials there are differences from 3 to $5^{\circ}$ of $\phi_{\text {max }}^{\prime}$ between the 914 and $71 \mathrm{~mm}$ diameter specimen. However, $\phi_{\max }^{\prime}$ varied less than $2^{\circ}$ for the specimens of $D_{100}=150$ and $50 \mathrm{~mm}(s=3)$. Thus, under the criteria of effectiveness previously defined, the PGM was corroborated for these three materials under $s=3$. Regarding particle breakage, it is confirmed a high amount of particle breakage for rock-piles materials (Pyramid dam a)

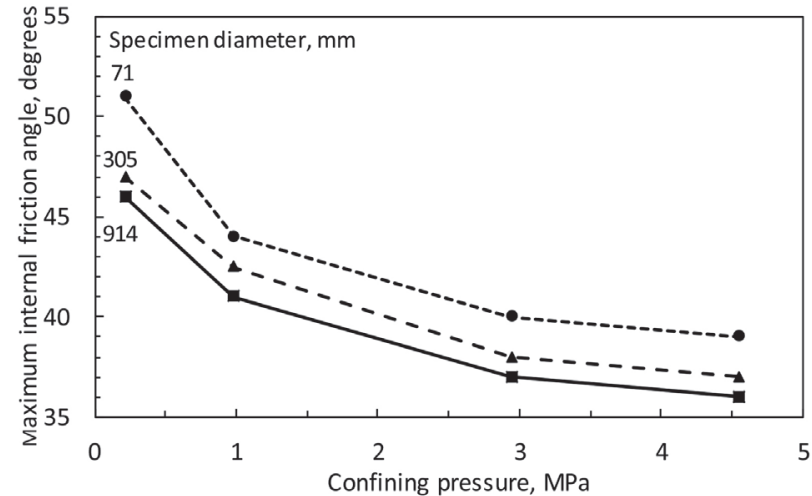

b)

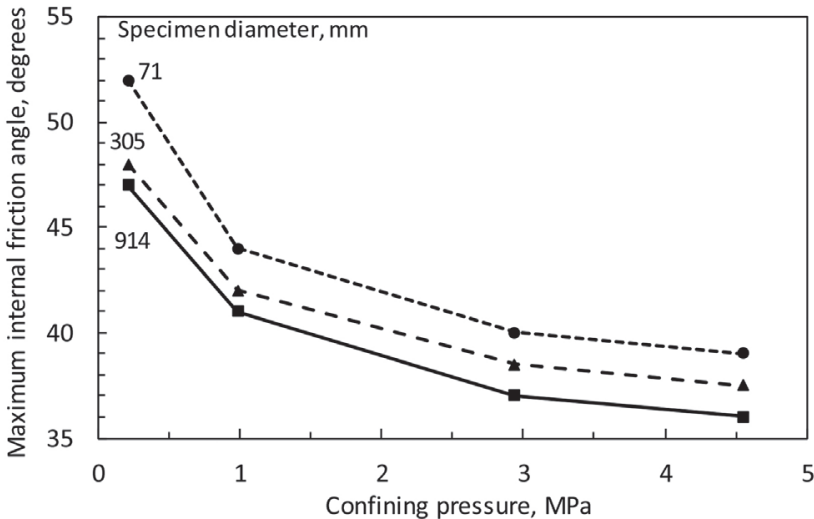

c)

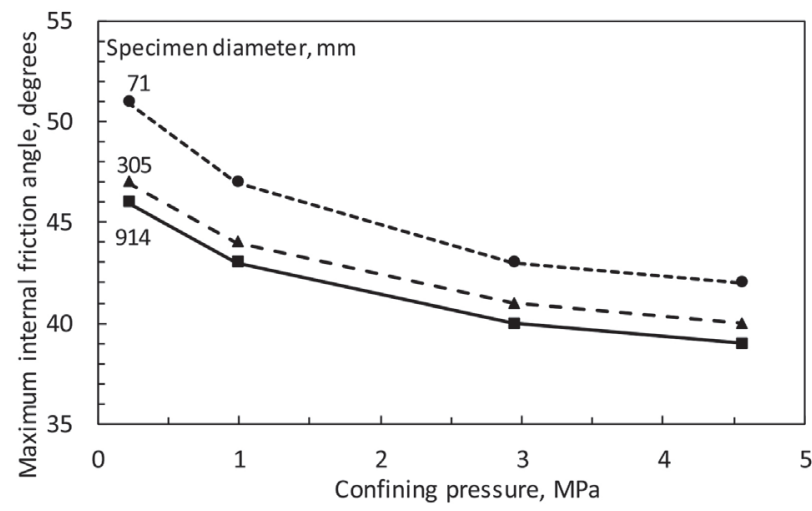

Figure 6: Maximum internal friction angle versus confining pressure for: a) Pyramid dam, b) crushed basalt and c) Oroville dam (Marachi et al., 1969)

material and crushed basalt), reaching a maximum $B_{\mathrm{g}}$ of 43 and 34, in contrast of Oroville material (sedimentary CGM) with a value of $B_{\mathrm{g}}=18$.

Becker et al. (1972) studied the effectiveness of the PGM for a sandstone rockfill. Gradations and internal friction angle results are presented in Figure 7. According to the maximum internal friction angle results, the difference of $\phi_{\max }^{\prime}$ among the three specimen sizes (diameters of 914, 305 and $71 \mathrm{~mm}$ ) is less than $3^{\circ}$, which confirmed the effectiveness of the PGM for a similitude ratio of up to 12. Regarding particle breakage, this material reached a 
maximum $B_{\mathrm{g}}$ of 33 , which is consistent with its material' nature (rock-pile).

Jernigan (1998) focused on studying the feasibility of using the PGM applied to crushed stone ballast. One of the materials tested was a Swedish ballast. Material characteristics are presented in Figures $8 \mathrm{a}$ and $8 \mathrm{~b}$. For this material, the difference between $\phi_{\text {max }}^{\prime}$ for the three scaled gradations is not greater than $3^{\circ}$ for each confining pressure, which is why this method is considered effective for this material $(s=4)$. Jernigan (1998) did not include explicitly particle breakage values, although it is assumed that negligible particle breakage was obtained, taking into account the particle's soundness for both materials, combined to a maximum confining pressure applied on testing of $200 \mathrm{kPa}$.

a)

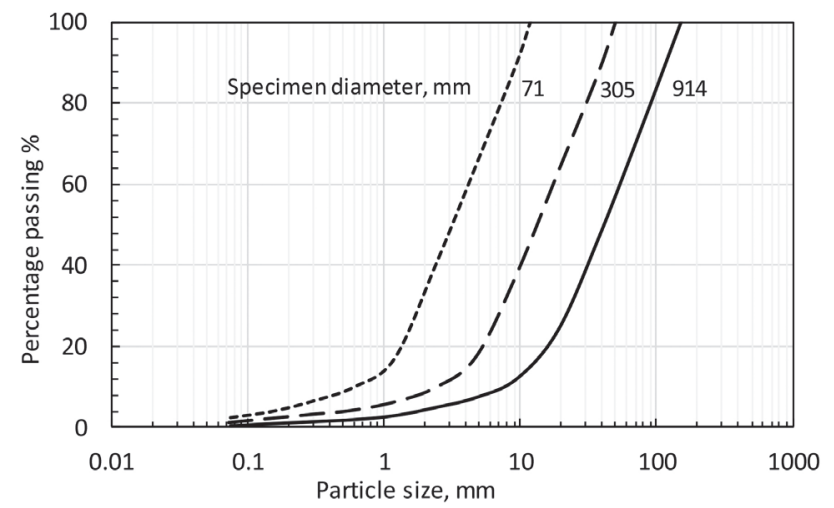

b)

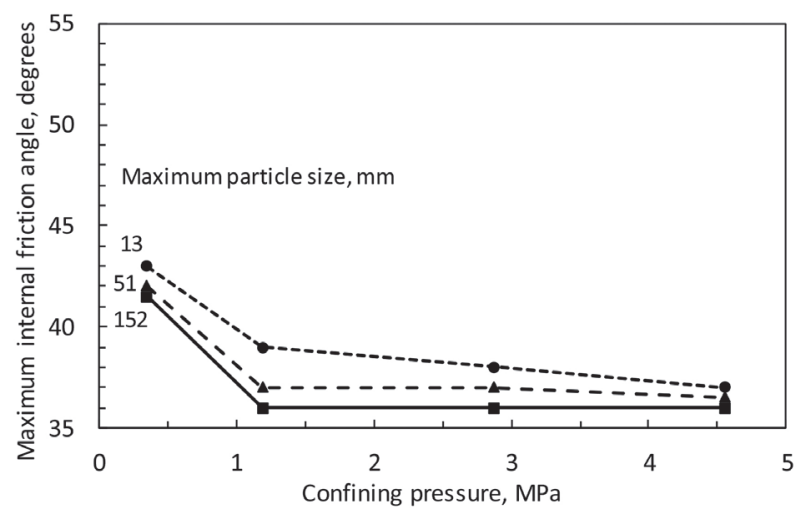

Figure 7: a) Gradations of Venato dam sandstone and b) maximum internal friction angle versus confining pressure (Becker et al., 1972)

Regarding the Quartzite material, Figures 9a and 9b show that, for the confining pressures of 20 and $160 \mathrm{kPa}$, the difference between $\phi_{\max }^{\prime}$ is less than $3^{\circ}$. However, for the pressures of 40 and $80 \mathrm{kPa}$, the difference is greater than $4^{\circ}$. Thus, the PGM was partially corroborated for this material ( $s=4.5$ for scaled samples). a)

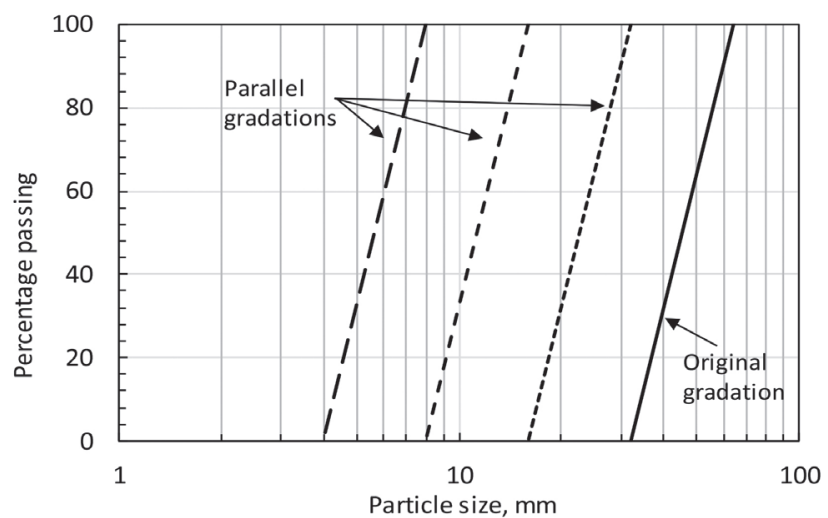

b)

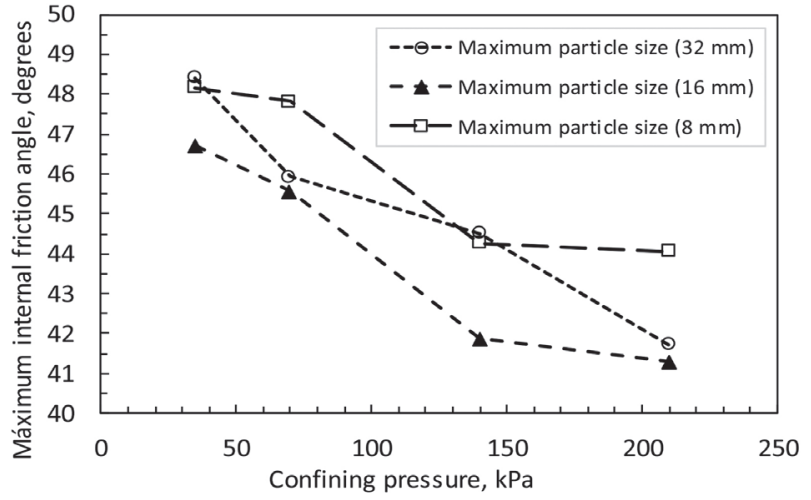

Figure 8: a) Gradation of Swedish ballast and b) maximum internal friction angle versus confining pressure (Jernigan, 1998)

a)

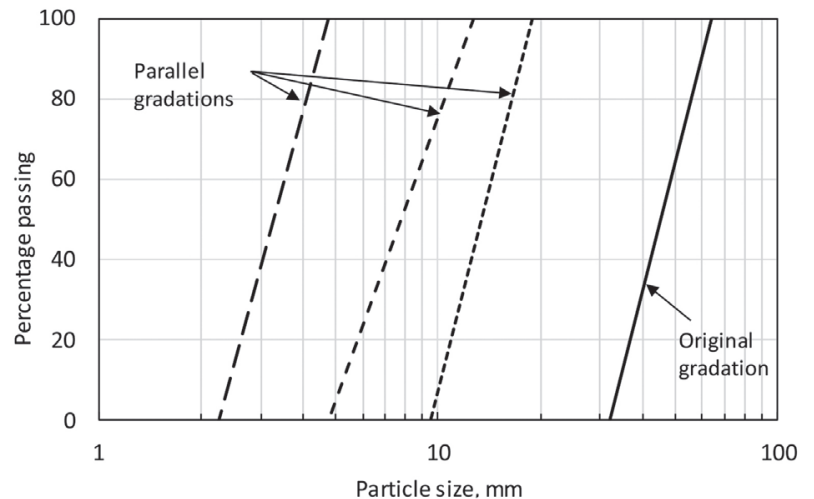

b)

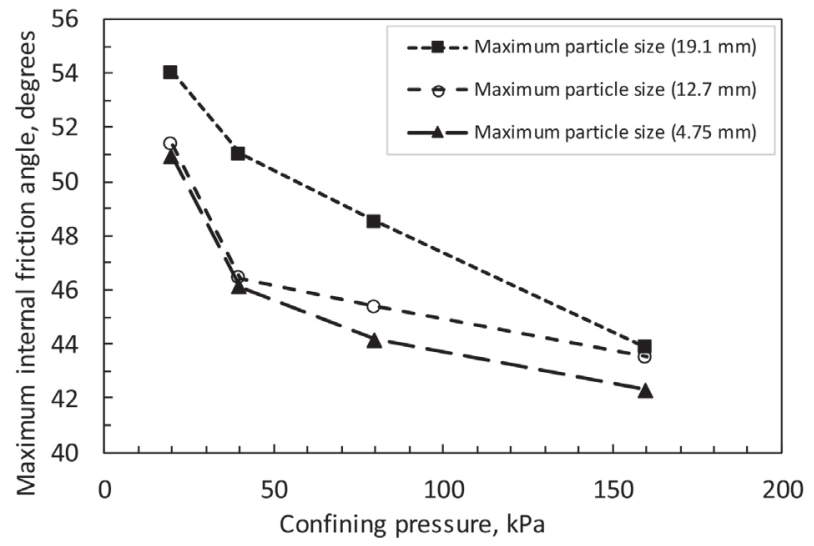

Figure 9: a) Gradation of Quartzite and b) maximum internal friction angle versus confining pressure (Jernigan, 1998) 
The studies by Verdugo et al. (2003) considered four sandy gravel type materials, of which two of them are discussed in this section. The first material was defined as A1, which corresponds to a gravel material from a river bed, with rounded particles and gradations as depicted in Figure 10a $(s=25)$. According to the results of $\phi_{\text {max }}^{\prime}$ shown in Figure $10 \mathrm{~b}$, the variation is no greater than $3^{\circ}$ except for a couple of tests (below $70 \mathrm{kPa}$ of confining pressure), which have a difference of more than $6^{\circ}$.

a)

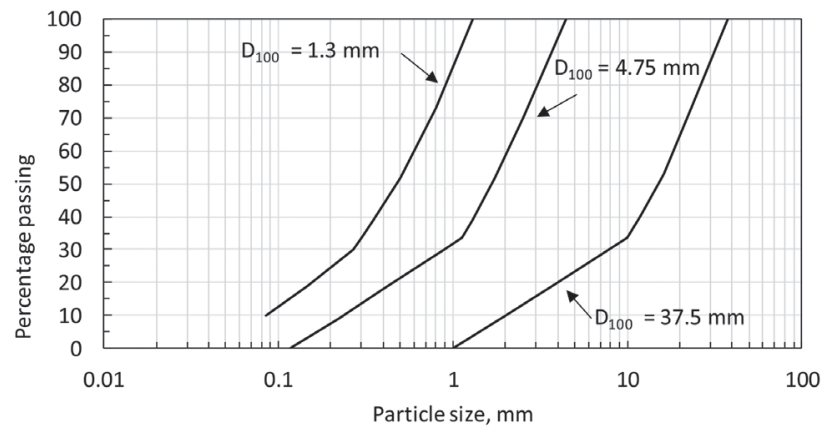

b)

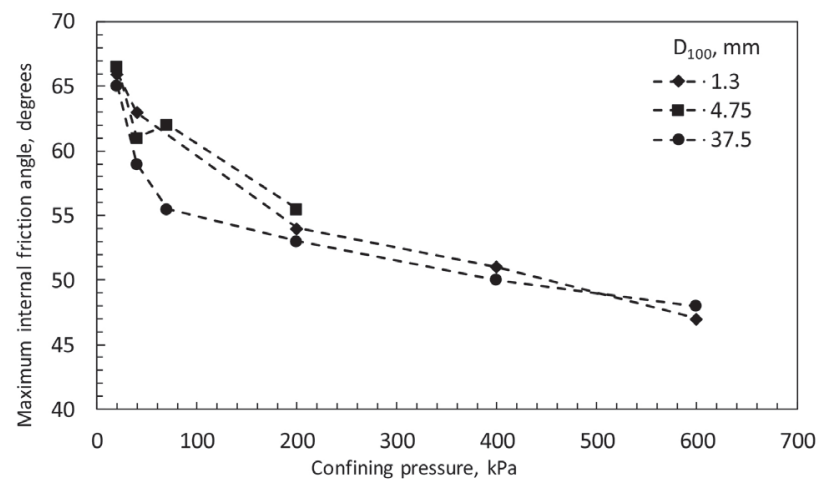

Figure 10: a) Gradations of A1 and b) maximum internal friction angle versus confining pressure (Verdugo et al., 2003)

The second material was defined as M1, which is also a river gravel, but of crushed type (subangular particles) that were acquired from an aggregate distributor. Four PSD represented in Figure 11a $(s=20)$ were analyzed. The results of $\phi_{\text {max }}^{\prime}$ shown in Figure 11b indicate that the variation of $\phi^{\prime}$ max for the four parallel gradations is between 3 and $5^{\circ}$, so the method was partially corroborated for this material.

Continuing the same line of research by Gesche (2002), de la Hoz (2007) studied a river bed gravel (with rounded to subrounded particles) and generated two sets of gradations (M2 and M3) with fines content lower than 10\% (both materials classified as sedimentary CGM). The material a)

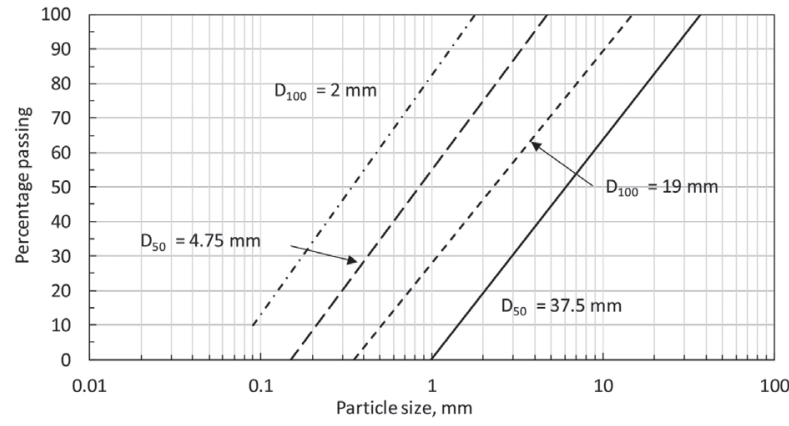

b)

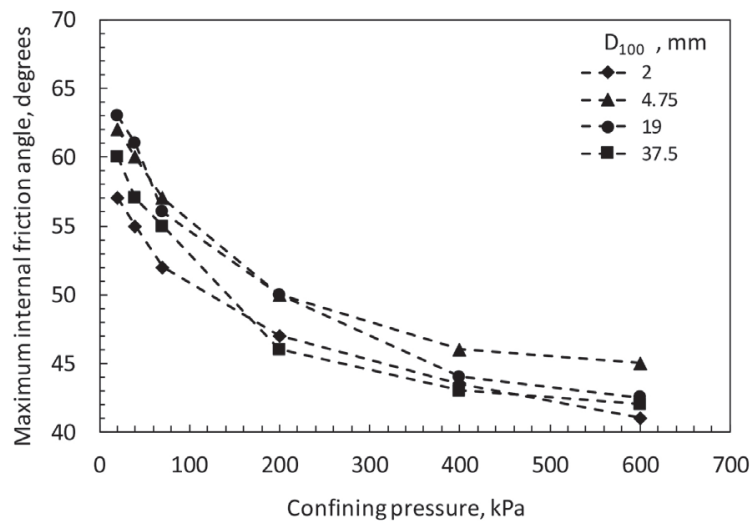

Figure 11: a) Gradations of M1 and b) maximum internal friction angle versus confining pressure (Verdugo et al., 2003)

a)

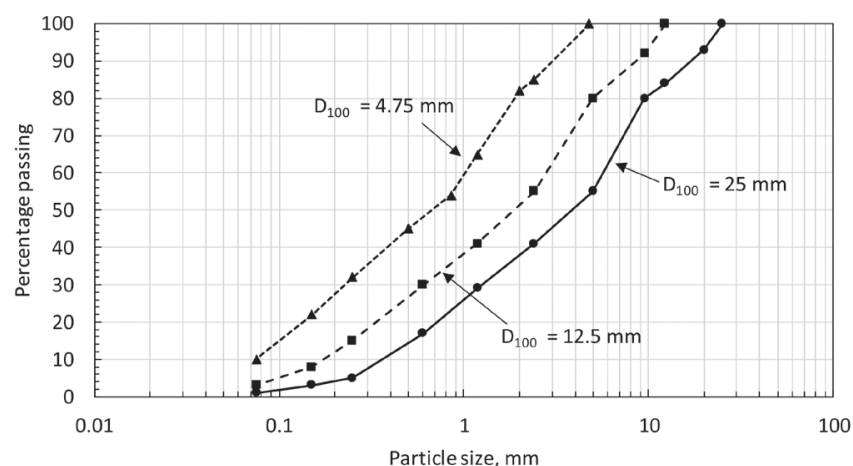

b)

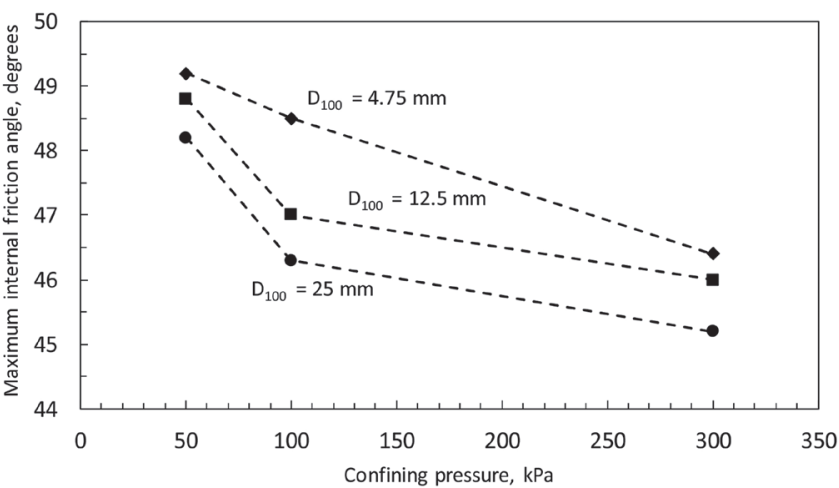

Figure 12: a) Gradation of $\mathrm{M} 2$ and b) maximum internal friction angle versus confining pressure (de la Hoz, 2007) 
a)

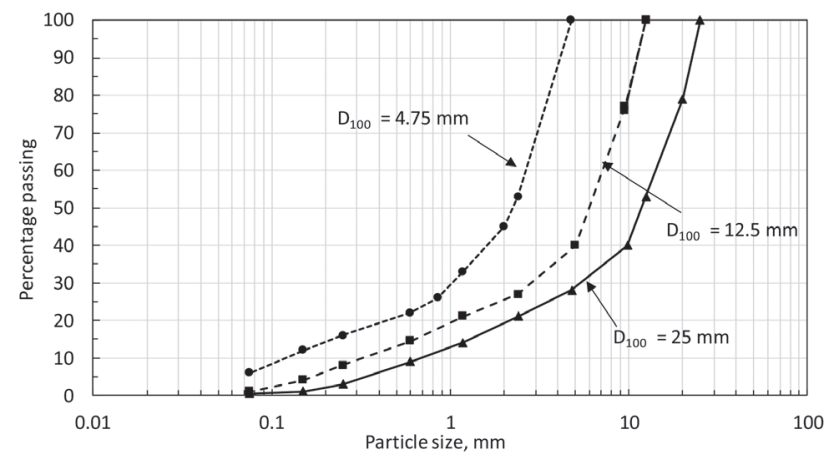

b)

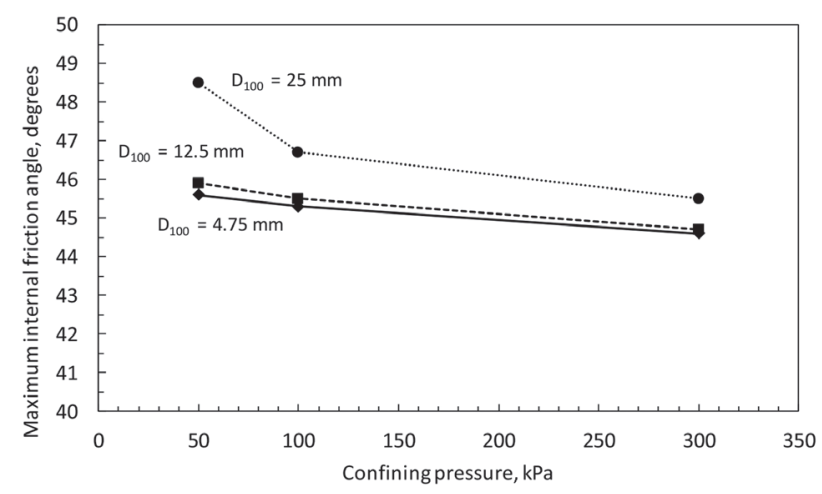

Figure 13: a) Gradation of $\mathrm{M} 3$ and b) maximum internal friction angle versus confining pressure (de la Hoz, 2007)

a)

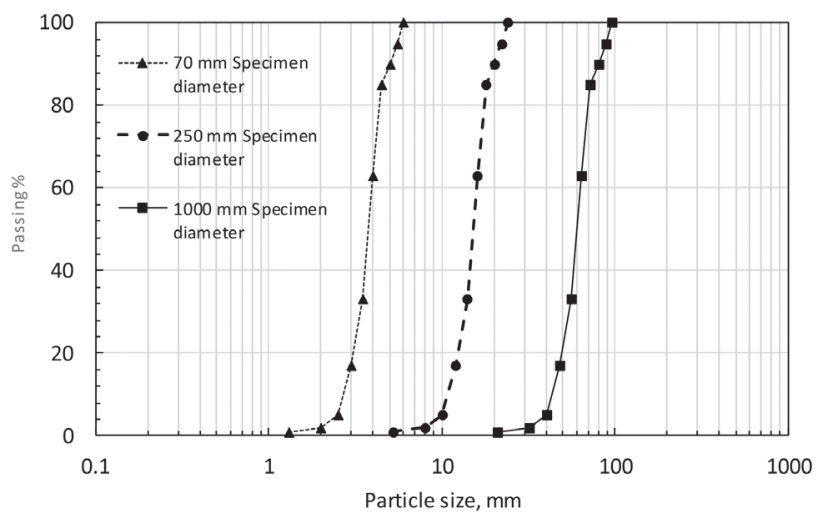

b)

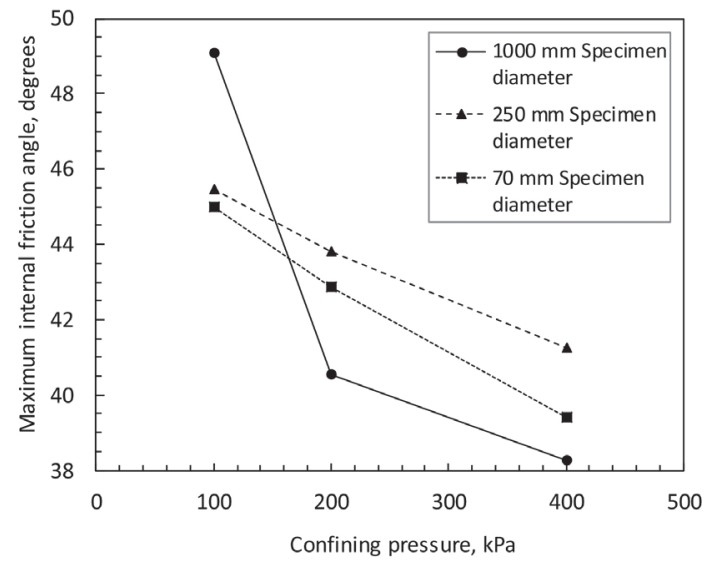

Figure 14: a) Gradation of limestone rock and b) maximum internal friction angle versus confining pressure (Hu et al., 2011)
M2 is presented with its gradations in Figure 12a $(s=$ 5.5). As shown in Figure 12b, $\phi^{\prime}{ }_{\max }$ varies between 1 and $2^{\circ}$, corroborating the effectiveness of the PGM for this material. Finally, results with the M3 material are shown in Figure 13, where it can be observed that the variation of $\phi_{\text {max }}^{\prime}$ is also less than $3^{\circ}$ for each applied confining pressure, also corroborating the PGM for this material $(s=5.5)$.

Moreover, Hu et al. (2011) analysed the effectiveness of PGM by testing a limestone rock. The PSD studied are shown in Figure 14a $(s=14)$. According to CID triaxial tests, the difference in $\phi_{\text {max }}^{\prime}$ for the 3 gradations analysed, resulted between 3 and $4^{\circ}$ for each confining pressure as can be observed in Figure 14b. In addition, it is highlighted a difference of $11^{\circ}$ for the $1000 \mathrm{~mm}$ specimen diameter for confining pressures between 100 and $400 \mathrm{kPa}$, which can be explained by the amount of particle breakage with $B_{\mathrm{g}}=$ 34 and 46, respectively.

\section{Considerations when using the PGM}

Despite the reliability of the PGM method (e.g. Jernigan, 1998; Verdugo and de la Hoz, 2006; Dorador, 2010), several properties must be kept between the original PSD and the model gradation to validate the method, which are developed through this section as follow.

\section{a) Maximum of $10 \%$ fines in model gradation samples}

The fines content significantly affects the shear strength and soil behaviour on granular materials (e.g. de la Hoz, 2007). Some types of CGM such as heap leap materials HLM, glacial tills and colluviums are more likely to have more than $10 \%$ of fines content impacting the effectiveness of the PGM. Even, PSD with less than $10 \%$ of fines content could also be not reliable for the use of the PGM because finer parallel gradations could reach fines content higher than $10 \%$ depending on how large the similitude ratio is.

\section{b) Parallelism between original and model gradations}

The parallel gradation is difficult to reach in practice because of the restriction of $10 \%$ of fines content on the model gradation to be kept. As a matter of fact, a common practice is to impose a fine content of $10 \%$ but loosing the parallelism at the finer branch of the model gradation as depicted in Figure 15, which will affect the effectiveness of the PGM (Dorador et al., 2017). 


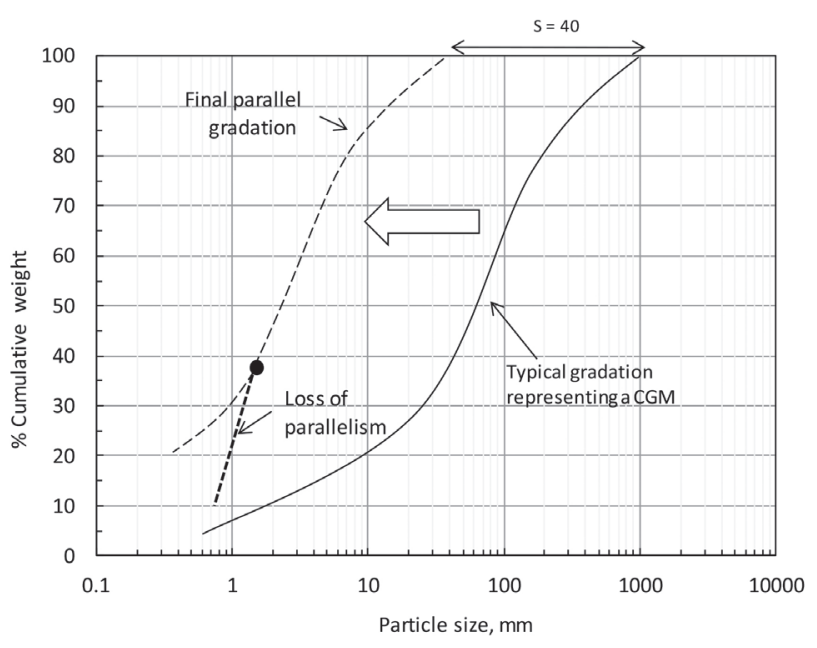

Figure 15: PGM affected by restriction of $10 \%$ of fines content

\section{c) Similar minimum and maximum density from original} to model gradations

The relative density $(\mathrm{RD})$ is a standard parameter used in granular soils (ASTM C128, 2015; ASTM D4253, 2016; ASTM D4254, 2016). Although RD has been questioned (e.g. Hamidi et al., 2013; Holtz, 1973), the use of the RD on CGM is the common practice when defining its compaction degree and is a recurrent parameter for laboratory testing when scaling between the original and model gradations. The main fact is to maintain similar minimum and maximum densities on CGM on both original and model gradations. However, the minimum density increases for larger $D_{50}$, which decreases the range of densities for original gradations (Abbas, 2012; Dorador, 2010; Riquelme and Dorador, 2017). Minimum and maximum density test results for samples are interpreted with parallel gradations, that is, using the same scale ratio for all particle sizes, and considering ASTM D4254 (2016) and thus avoiding issues associated with sample preparation. This can be explained in part by a combined effect of selfweight of larger particles, changes in particle's roughness for different sizes and a segregation process during testing, which tends to compress smaller particles during the procedure of pouring under the standard ASTM D4254 (2016). The implications of this finding are that RD is not an ideal parameter to compare densities of both original and model gradations, and probably the Relative Compaction parameter RC (Tavenas et al., 1973), expressed in equation (1) as a function of the dry unit weight $\gamma_{d}$ and maximum dry unit weight $\gamma_{\text {dmax }}$, is a more reliable parameter to use when applying the PGM on CGM. This is a topic under ongoing investigation which may improve the choice of density of model gradation samples regarding in-situ and laboratory testing.

$$
\mathrm{RC}=\frac{\gamma_{d}}{\gamma_{d \max }}
$$

\section{d) Maintain particle shape between original and parallel PSD}

The change in particle shape between the original and parallel PSD is one of the major drawbacks of this method. There are several studies regarding the influence of particle shape in terms of its implication on mechanical properties on granular soils (e.g. Koerner, 1970; Santamarina and Cho, 2004; Vallerga et al., 1957). Certainly, CGM experience changes in particle shape under different ranges of particle sizes. The first example are coarse fluvial soils, whose particles could be rounded and subrounded under gravel sizes, but subrounded to subangular on sands sizes (e.g. Gesche, 2002; Marachi et al., 1969). By comparison, quarry rockfill materials, HLM and MWRM, can inherit large particles with high aspect ratios from the parental rock and influenced by blasting, but they can contain smaller and more spherical angular particles at smaller sizes. A case study regarding the change of particle shape for different particle sizes was introduced by de la Hoz (2007). This author studied a riverbed rockfill material containing large subangular, with high aspect ratio particles, but smaller rounded to subrounded particles. Results of triaxial compression CID tests indicate variations of $\phi_{\text {max }}^{\prime}$ between 12 and $14^{\circ}$ under a consolidation pressure of 100 to $400 \mathrm{kPa}$ between original and model gradation $(s=21)$. Le Penn et al. (2013) have proposed a practical procedure to characterize the particle shape, which can contribute in controlling the particle shape on scaled samples. Thus, it is recommended to use low similitude ratios to avoid significant change of particle shape between the original and model gradation.

\section{e) Maintain mineralogy and compressive strength on particles}

This is probably the main drawback of this method. As explained before in the section of classification in terms of origin, the particle's strength changes for some CGM depending on its particle size, which affect directly the 
effectiveness of this method. This issue is also pointed out by Parkin (1991), who states that scaled samples may be obtained from fine components, which often form from inferior material. Thus, four practical cases, which depend on the particle strength of a CGM, are developed as follow:

Case 1: Particle's strength does not change with size: Under this case, the parallel gradation method PGM works. Coarse fluvial and alluvial soils, strong crushed ballasts and quarry rockfills of sedimentary rocks (e.g. sandstone, limestone) are examples of CGM that may classify under this designation.

Case 2: Particle's strength decreases for larger particles: It is well accepted the size-scale effect on single rocks explained by the fact that larger particles have a greater likelihood of containing defects, veins, and smaller discontinuities, which contribute to weakening the block. As a matter of fact, a shear strength model considering the size-scale effect has been proposed by Frossard et al. (2012). Examples of CGM for case 2 are MWRM, quarry rockfills from igneous and metamorphic rocks and BOM.

Case 3: Particle's strength decreases for smaller and larger particles: As explained for case 2, CGM can decrease their shear strength and stiffness properties for larger particles, although an additional scale effect can be noticed from gravel sizes towards sands. For instance, in case of considering a heterogeneous CGM such as quarry rockfills or MWRM, a portion of smaller particles could be the result of weaker components of the parental rock (e.g. weathered rock), which result in a lower shear strength of this portion of material when compared with larger particles of the CGM (e.g. gravels). Another example is a coarse heap leach material HLM, whose particles can be weaker for smaller sizes due to chemical weathering and weaker for larger particles as well (due to the inherit of the parental rock).

Case 4: Particle's strength decrease for smaller particles: This case is a particular scenario of case 3 in which the effect of larger particles in decreasing the overall mechanical properties is negligible. HLM with a few percentages of large particles and some coarse alluvial and fluvial materials are example of this case.

Therefore, based on these four cases, a chart is provided in Figure 16. This chart is intended to identify how the overall shear strength and deformation modulus of the CGM will change for different $D_{50}$ values.
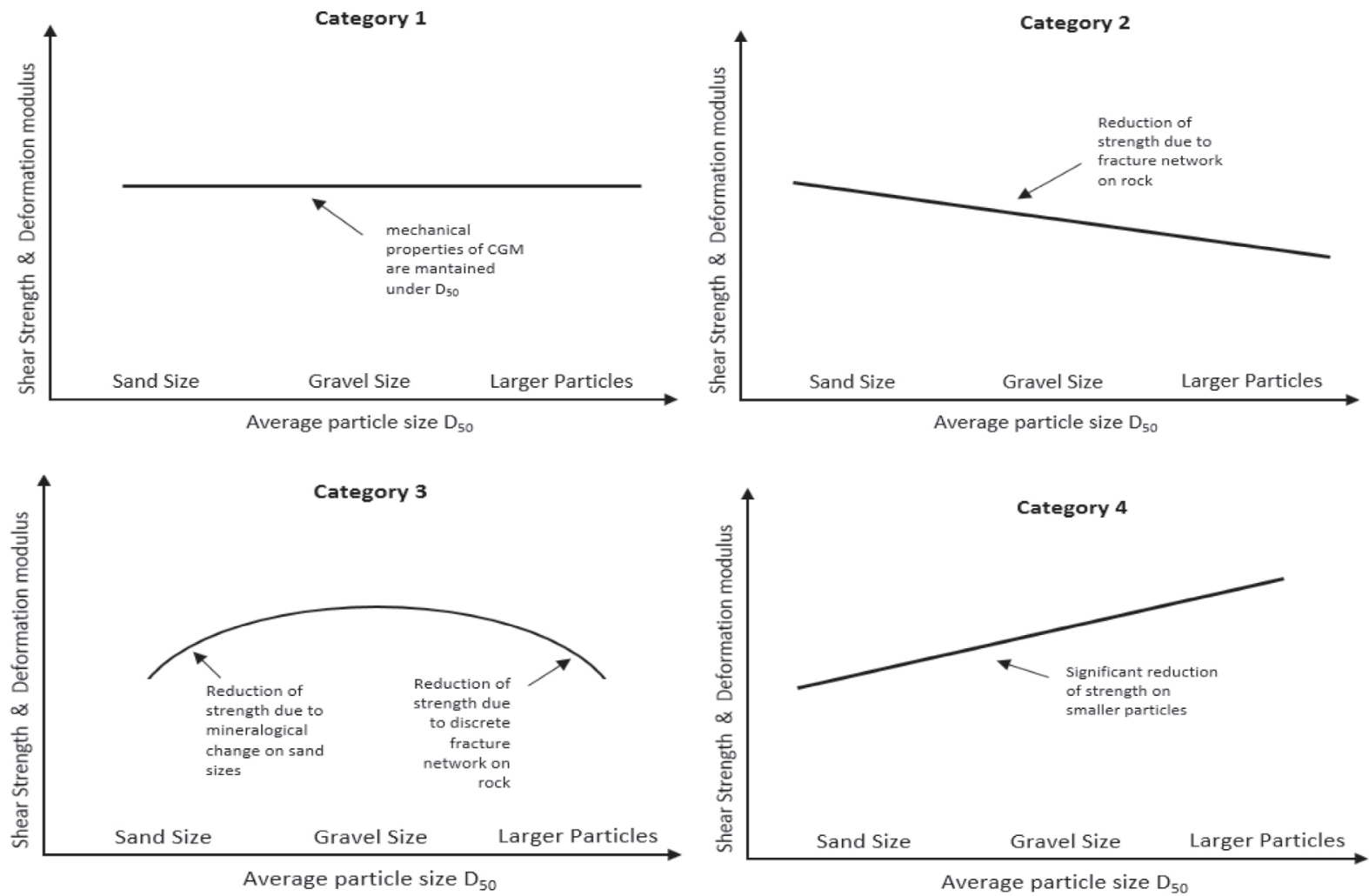

Figure 16: Four cases of CGM showing how the mechanical properties vary based on the compressive strength of particles 


\section{f) Mixture of particles of different strength on CGM}

Mixtures of different particle's strength on CGM is quite common in practice. Some examples are quarry rockfills and waste rock piles from different rock sources. However, few studies are available regarding to how weak particles affect the mechanical properties of the overall material. Authors such as Valdes and Leleu (2008), D’Espessailles et al. (2014) and Wang et al. (2016) have reported laboratory shear strength testing programmes on mixed sands, while Dorador and Urrutia (2017) reported a case study of geotechnical properties of a rockfill material with different percentages of weathered and sound particles. More studies are required to develop this topic, although for practical purposes, the overall $\phi_{\max }^{\prime}$ of both weak and strong coarse materials $\left(\phi_{\mathrm{w}}^{\prime}\right.$ and $\left.\phi_{\mathrm{st}}^{\prime}\right)$ could be approximated as a weighted average of the particle content percentage of both weak $C_{w}$ and strong $C_{\mathrm{st}}$ particles as:

$$
\phi^{\prime}=\frac{\phi_{w}^{\prime} C_{w}+\phi_{s t}^{\prime} C_{s t}}{100}
$$

\section{Recommendations when using the PGM on coarse granular materials}

The parallel gradation method PGM is a procedure to scale geotechnical properties of CGM by means of a small portion of material. Figure 17 provides a chart of recommended similitude ratio $s$ for several types of CGM. However, it is not recommended to scale too far (Parkin, 1991), because the particle properties of both original and scaled samples can change dramatically. Two types of representative CGM will be treated. In addition, laboratory testing aiming to evaluate the mechanical properties of CGM are also discussed.

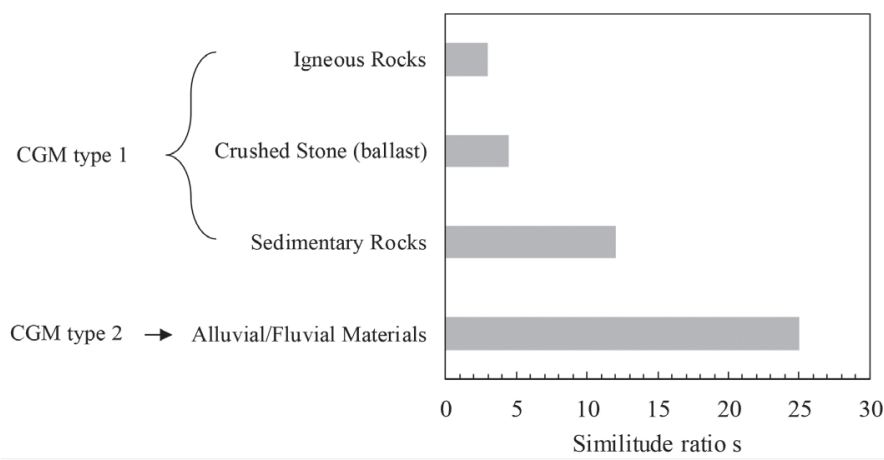

Figure 17: Recommended similitude ratio $s$ for CGM when applying the PGM

\section{Type 1 gradation: coarse uniform gradations}

Two types of uniform gradations are defined in Figures 18. Gradation Type 1A is a full uniform gradation, which is ideal in terms of scaling using PGM, which is consistent with the recommendations by Parkin (1991) of using the PGM for hard rocks and narrow gradations. Type 1B is the typical uniform gradation with some oversize particles. For this example, it is recommended the PGM and scalping up to a $20 \%$ of oversize.

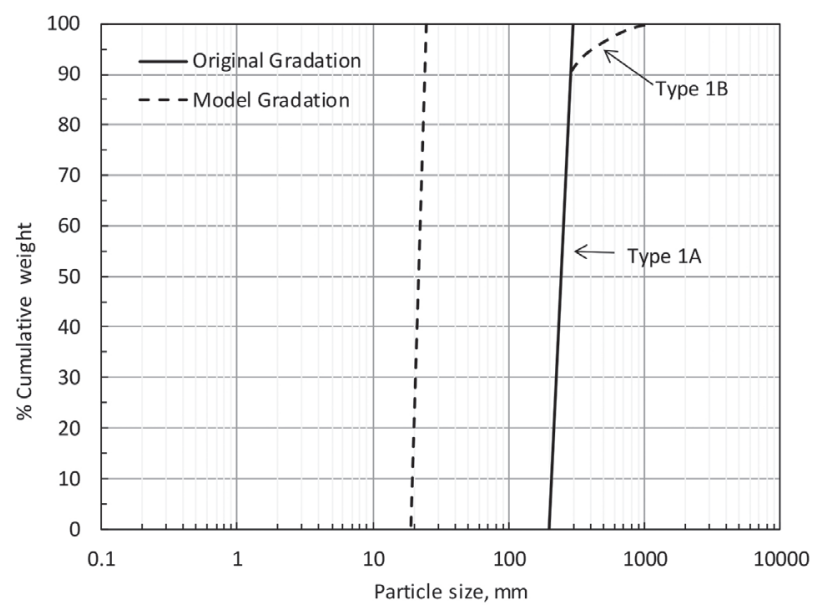

Figure 18: Types of coarse gradations for PGM (type 1)

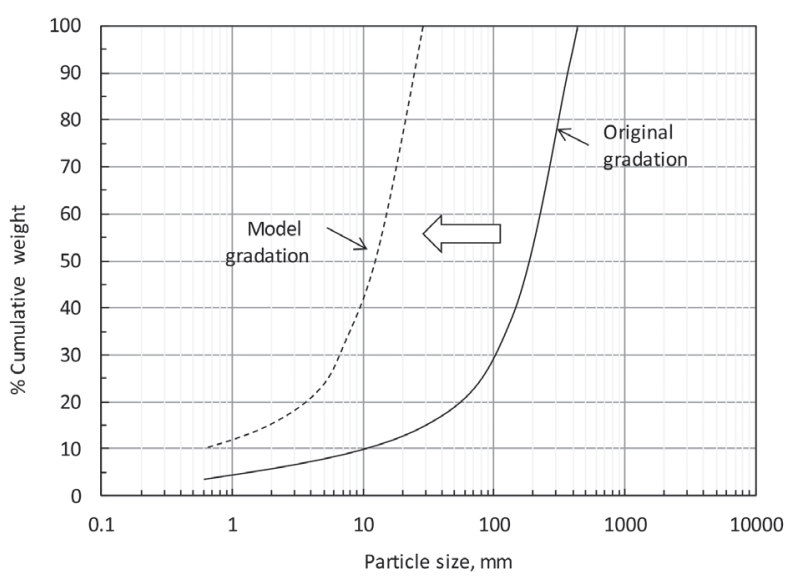

Figure 19: Types of coarse gradations for PGM (Type 2)

\section{Type 2: uniform coarse gradations with fine gradation}

Figure 19 depicts some uniform coarse gradations with fine gradation which is frequent in MWRM and quarry rockfills. The PGM can be applied specially considering the restriction of $10 \%$ of fines and keeping similar particle strength on original and model gradations. A key issue on this type of gradation is that the fine branch could affect 
the mechanical properties of the CGM. As the particles belonging to the fine gradation branch are significantly smaller that the average size of coarser particles, then the fine branch reduces the strength of the overall CGM. Thus, the use of the PGM on Type 2 gradations must be applied with caution, specially maintaining the parallelism between original and model gradations.

\section{Final remarks}

Coarse granular materials (CGM) usually require procedures to scale the size of large particles for geotechnical characterization purposes, for instance the assessment of shear strength. In this work the effectiveness of the parallel gradation method (PGM), which consists in scaling samples with coarse particles (larger than $75 \mathrm{~mm}$ ) through smaller particles using the same scale ratio for all particle sizes, was analysed. The effectiveness of the PGM was analysed in terms of maximum internal friction angle under specific materials types (alluvial/fluvial materials, crushed stone ballasts, igneous and sedimentary rockfills).

CGM should not be considered directly as scaleindependent when considering the PGM except when the intrinsic grain properties among the original and scaled gradations are maintained, which has been corroborated only on specific CGM such as fluvial/alluvial materials, crushed ballasts, and some rockfills from sedimentary rock origin. The next recommendations should be considered when using the PGM: a) adopt a maximum of $10 \%$ fines in model gradation samples, b) keep parallelism between original and model gradations, c) keep similar minimum and maximum density from original to model gradations, d) maintain particle shape between original and parallel PSD, e) maintain mineralogy and compressive strength on particles and $\mathrm{f}$ ) balance for mixture of particles of different strength on CGM.

In addition, the application of the PGM on rockfills from igneous rocks represents a major challenge and should be used with major caution. Thus, recommendations in the use of the PGM for different size scaling factors (similitude ratio $s$ ) for several types of CGM are provided, and the use of others scaling methods (e.g. scalping method) should be considered in case the PGM cannot be applied.

Another relevant remark is that the minimum dry unit weight increases for larger $D_{50}$, which means that when comparing parallel gradations based on the relative density $\mathrm{RD}$, the actual density of each material will be different. Thus, it is recommended the use of the relative compaction parameter RC, which relies on the dry unit weight and maximum dry unit weight only.

\section{References}

Abbas, A.M. (2012). Uncompacted void content versus maximum particle size for rockfill materials. International Journal of Engineering Science and Technology 4(1), 197-203

ASTM C128 (2015). Standard test method for relative density (specific gravity) and absorption of fine aggregate. ASTM International, West Conshohocken, PA, USA

ASTM D4253 (2016). Standard test methods for maximum index density and unit weight of soils using a vibratory table. ASTM International, West Conshohocken, PA, USA

ASTM D4254 (2016). Standard test methods for minimum index density and unit weight of soils and calculation of relative density. ASTM International, West Conshohocken, PA, USA

Bareither, C.A., Benson, C.H. and Edil, T.B. (2006). Reproducibility of direct shear tests conducted on granular backfill materials. Geotechnical Testing Journal 31(1), 84-94

Becker, E., Chan, C.K. and Seed, H.B. (1972). Strength and deformation characteristics of rockfill materials in plane strain and triaxial compression tests. Report No TE-72-3. Dept. of Civil Engineering, University of California, Berkeley, USA

de la Hoz, K. (2007). Estimation of the shear strength parameters of coarse granular materials. MSc thesis, University of Chile, Santiago, Chile (in Spanish)

D’Espessailles, N., Dorador, L. and Pastén, C. (2014). Particle breakage in blasting sands from a mining tunnel under simple shear stresses. IV South-American Young Geotechnical Engineering Conference. Bogotá, Colombia (in Spanish)

Dewangan, P.K., Pradhan, M. and Ramtekkar, G.D. (2015). Effect of fragment size, uniformity coefficient and moisture content on compaction and shear strength behavior of coal mine overburden dump material. European Journal of Advances in Engineering and Technology 2(12), 1-10

Dorador, L. (2018). Una revisión de la metodología de granulometría paralela o escalamiento de curvas homotéticas aplicado a la caracterización geotécnica de materiales granulares gruesos. X Congreso Chileno de Geotecnia, Valparaíso, paper 1259 
Dorador, L. (2010). Experimental analysis of the methodologies of homothetic and shear curves in the geotechnical property evaluation of coarse soils. MSc thesis, University of Chile, Santiago, Chile (in Spanish)

Dorador, L. and Urrutia, J. (2017). Geotechnical characterisation of coarse-grained soils containing weak and strong particles mixtures. $70^{\text {th }}$ Canadian Geotechnical Conference, GeoOttawa 2017, Ottawa, ON, Canada

Dorador, L., Anstey, D. and Urrutia, J. (2017). Estimation of geotechnical properties on leached coarse material. $70^{\text {th }}$ Canadian Geotechnical Conference, GeoOttawa 2017, Ottawa, ON, Canada Frossard, E., Hu, W., Dano, C. and Hicher, P.Y. (2012). Rockfill shear strength evaluation: a rational method based on size effects. Géotechnique 62(5), 415-427

Fu, W.X. and Dai, F. (2015). Scale dependence of shear strength for a coarse granular soil using a superimposition-nest type of direct shear apparatus. Arabian Journal of Geosciences 8(12), 10301-10312 Gesche, R. (2002). Evaluation methodology of the shear strength parameters of coarse grained soils. Civil Engineer degree project. University of Chile, Santiago, Chile (in Spanish)

Hamidi, B., Varaksin, S. and Nikraz, H. (2013). Relative density concept is not a reliable criterion. Proceedings of the Institution of Civil Engineers: Ground Improvement 166(2), 78-85.

Holtz, W.G. (1973). The relative density approach - uses, testing requirements, reliability, and shortcomings. Evaluation of Relative Density and Its Role in Geotechnical Projects Involving Cohesionless Soils, Selig, E. and Ladd, R., (eds.). ASTM STP 523, 5-17 Honkanadavar, N.P. and Sharma, K.G. (2016). Modeling the triaxial behavior of riverbed and blasted quarried rockfill materials using hardening soil model. Journal of Rock Mechanics and Geotechnical Engineering 8(3), 350-365

Hu, W., Dano, C., Hicher, P.Y., Le Touzo, J.Y., Derkx, F. and Merliot, E. (2011). Effect of sample size on the behavior of granular materials. Geotechnical Testing Journal 34(3), 186-197

Idel, K.H. (1960). Die Scherfestigkeit rolliger Erdstoffe. Veröffentlichungen des Institutes für Bodenmechanik und Grundbau der Technischen Hochschule Fridericiana in Karlsruhe, Germany (in German)

Jernigan, R.L. (1998). The physical modeling of soils containing oversized particles. $\mathrm{PhD}$ thesis, University of Colorado at Boulder, USA
Kim, D. and Ha, S. (2014). Effects of particle size on the shear behavior of coarse grained soils reinforced with geogrid. Materials 7(2), 963-979

Koerner, R.M. (1970). Effect of particle characteristic on soil strength. Journal of the Soil Mechanics and Foundations Division 96(4), 1221-1233

Le Pen, L.M., Powrie, W., Zervos, A., Ahmed, S. and Aingaran, S. (2013). Dependence of shape on particle size for a crushed rock railway ballast. Granular Matter 15(6), 849-861

Leslie, D.D. (1963). Large scale triaxial tests on gravelly soils. Second PanAmerican Conference on Soil Mechanics and Foundation Engineering, Brazil, 181 - 202

Lowe, J. (1964). Shear strength of coarse embankment dam materials. $8^{\text {th }}$ International Congress on Large Dams, Edinburgh, UK. vol.3, 745-761

Marachi, N.D., Chan, C.K., Seed H.B. and Duncan, J.M. (1969). Strength and deformation characteristics of rock fill materials. Report No. TE-969-5, Department of Water Resources, University of California, Berkeley, California, USA

Marsal, R.J. (1973). Mechanical properties of rockfill. Embankment Dam Engineering, Casagrande volume, R.C. Hirshfield and S.J. Polous (eds.), John Wiley \& Sons Inc., New York, USA, 109-200

Parkin, A.K. (1991). Through and overflow rockfill dams. Advances in Rockfill Structures, E. Maranha das Neves (ed.), Kluver Academic Publishers, The Netherlands, 571-592

Riquelme, J. and Dorador, L. (2017). Methodology to determine maximum and minimum void index in coarse granular soils from small-scale tests correlations. $70^{\text {th }}$ Canadian Geotechnical Conference, GeoOttawa 2017, Ottawa, ON, Canada

Santamarina, J.C. and Cho, G.C. (2004). Soil behaviour: The role of particle shape. Advances in Geotechnical Engineering: The Skempton Conference, Thomas Telford, London, UK, vol. $1,604-617$

Tavenas, F.A., Ladd, R.S. and La Rochelle, P. (1973). Accuracy of relative density measurements: results of a comparative test program. Evaluation of Relative Density and its Role in Geotechnical Projects Involving Cohesionless Soils, Selig, E. and Ladd, R., (eds.). ASTM STP 523, American Society for Testing and Materials, 18-60 
Valdes, J.R. and Leleu, S.L. (2008). Influence of mineral composition on the simple shear response of sands: Experimental study. Journal of Geotechnical and Geoenvironmental Engineering 134(12), 1820-1824

Vallerga, B.A., Seed, H.B., Monismith, C.L. and Cooper, R.S. (1957). Effect of shape, size, and surface roughness of aggregate particles on the strength of granular materials. Road and Paving Materials: Second Pacific Area National Meeting, American Society for Testing and Materials, Los Angeles, California, USA, ASTM STP 212, 63-74

Varadarajan, A., Sharma, K.G., Abbas S.M. and Dhawan, A.K. (2006). The role of nature of particles on the behaviour of rockfill materials. Soils and Foundations 46(5), 569-584

Varadarajan, A., Sharma, K.G., Venkatachalam, K. and Gupta, A.K. (2003). Testing and modeling two rockfill materials. Journal of Geotechnical and Geoenvironmental Engineering 129(3), 206-218
Verdugo, R. and de la Hoz K. (2006). Strength and stiffness of coarse granular soils. Geotechnical Symposium Soil Stress Strain Behaviour: Measurement, Modelling and Analysis. Rome, March 16-17, H.I. Ling, L. Callisto, D. Leshchinsky, and J. Koseki (eds.), Springer, Dordrecht, The Netherlands, 243-252

Verdugo, R., Gesche, R. and De la Hoz, K. (2003). Evaluation methodology of the shear strength parameters of coarse granular soils. $12^{\text {th }}$ Pan American Conference on Soil Mechanics and Geotechnical Engineering, Cambridge, MA, USA, vol. 1, 691696 (in Spanish)

Wang, J.J., Qiu, Z.F., Deng, W.J. and Zhang, H.P. (2016). Effects of mudstone particle content on shear strength of a crushed sandstone-mudstone particle mixture. Marine Georesources \& Geotechnology 34(4), 395-402 